\title{
Taller de metodología etnográfica en Antropología y Sociología
}

Bogotá, 12-16 de marzo de 2007

\section{Virginie Laurent}

\section{(2) OpenEdition}

Journals

Edición electrónica

URL: http://journals.openedition.org/bifea/3762

DOI: 10.4000/bifea.3762

ISSN: 2076-5827

\section{Editor}

Institut Français d'Études Andines

\section{Edición impresa}

Fecha de publicación: 1 diciembre 2007

Paginación: 455-458

ISSN: 0303-7495

\section{Referencia electrónica}

Virginie Laurent, «Taller de metodología etnográfica en Antropología y Sociología », Bulletin de l'Institut français d'études andines [En línea], 36 (3) | 2007, Publicado el 01 junio 2008, consultado el 08 diciembre 2020. URL : http://journals.openedition.org/bifea/3762 ; DOI : https://doi.org/10.4000/bifea. 3762

Les contenus du Bulletin de l'Institut français d'études andines sont mis à disposition selon les termes de la licence Creative Commons Attribution - Pas d'Utilisation Commerciale - Pas de Modification 4.0 International. 


\section{Eventos}

\section{TALLER DE METODOLOGÍA ETNOGRÁFICA EN ANTROPOLOGÍA Y SOCIOLOGÍA}

Bogotá, 12-16 de marzo de 2007

Del 12 al 16 de marzo de 2007, se realizó en Bogotá un Taller de Metodología Etnográfica en Antropología y Sociología, convocado por el Instituto Francés de Estudios Andinos (IFEA) y el Centro de Estudios Mexicanos y Centroamericanos (CEMCA). Unas semanas después, del 21 al 25 de mayo, la iniciativa se repitió en la Ciudad de México.

Partiendo de la voluntad de fortalecer vínculos interinstitucionales, los dos talleres tuvieron lugar con el auspicio de la Pontificia Universidad Javeriana y la Universidad Nacional Autónoma de México respectivamente, bajo la coordinación conjunta de investigadoras/ es y profesoras/es procedentes de centros de investigación y universidades de Francia, Colombia y Mexico: Anath Ariel de Vidas (Cemca) y Virginie Laurent (IFEA), con Margarita Chaves Cháves (Instituto Colombiano de Antropología e Historia) y Martha Zambrano (Departamento de Antropología, Facultad de Ciencias Humanas de la Universidad Nacional de Colombia) en Colombia, y Cristina Oehmichen (Instituto de Investigaciones Antropológicas de la Universidad Autónoma de México) y Saúl Millán (Escuela Nacional de Antropología e Historia) en México.

En ambos países el taller estaba dirigido a estudiantes e investigadores interesados en integrar un espacio común de discusión metodológica a partir de experiencias individuales y colectivas de investigación en ciencias sociales. Con el fin de hacer más concreto el ejercicio metodológico, y estimular también análisis de índole temática, se hizo un llamado especial a candidatos estudiosos de temas afines a los de la multiculturalidad y las interacciones sociales en escenarios públicos en América Latina.

Según indica el alto número de respuestas que motivaron las convocatorias para cada uno de estos encuentros, se revela un gran interés por «aprender a etnografíar» entre profesionales de un amplio abanico de disciplinas. Antropólogos y sociólogos, pero también psicólogos, historiadores, politólogos, fueron muchas las personas que, tanto en Colombia como en México, expresaron su motivación para participar en el taller, tendiendo así a demostrarse que la investigación etnográfica se viene convirtiendo en una herramienta válida no solo y exclusivamente para los etnólogos. Finalmente, veinticinco integrantes fueron seleccionados entre más de ochentas candidaturas para cada taller. Estos respondían a variados perfiles y 
formación — desde estudiantes de pregrado hasta candidata/os a doctorado en las múltiples áreas mencionadas - quienes estaban todos dispuestos a prestarse a las reglas del juego de un ejercicio interactivo estructurado alrededor de cinco jornadas de trabajo intensivo.

Pensado bajo la dimensión de un seminario que combinara presentaciones por parte de las/os coordinadoras/es, (re)activa participación de las/os asistentes y una tarea práctica de etnografía, el taller apuntaba a facilitar el perfeccionamiento de las propuestas de investigación de las/os asistentes al ofrecer un espacio para compartir experiencias, avances y dudas tanto en cuanto a contenido temático como a opciones metodológicas.

Para dicho fin, se trazaron tres principales direcciones de trabajo. En primer lugar, se buscó precisar la manera cómo se definen estrategias de indagación, herramientas metodológicas y perspectivas de aproximación a terrenos apropiadas en función de los temas y problemas de investigación (desde diferentes disciplinas, enfoques, escalas espacio-temporales). Desde allí, se apuntó a evaluar la validez del recurso a una serie de técnicas e instrumentos metodológicos de índole cuantitativa y cualitativa (estadísticas, encuestas, sondeos, observación de terreno, entrevistas, historias de vida, entre otros). Por último, se sugirió reflexionar en la comparación como herramienta de investigación a partir de las siguientes preguntas: ¿Qué comparar? ¿Cómo comparar? ¿Para qué sirve comparar?

Después de una primera jornada empleada para «conocerse mejor» entre participantes a través de una presentación corta de las trayectorias y los trabajos de unas/os y otras/os, una segunda sesión fue dedicada a una reflexión colectiva a partir de comunicaciones orales a cargo de las/os coordinadoras/es del taller, seguidas por sesiones de discusión y relativas a temas centrales en torno a procedimientos metodológicos: la comparación en la antropología como estrategia y como mirada específica (Anath Ariel De Vidas), el debate y la posible complementariedad entre métodos cuantitativos y cualitativos en sociología (Virginie Laurent), así como las dimensiones políticas en el trabajo de campo en antropología (Margarita Chaves), el problema de las fuentes y su dimensión interdisciplinaria (Martha Zambrano) para el taller realizado en Colombia, el trabajo de campo en contextos urbanos (Cristina Oehmichen), etnografía y diversidad cultural (Saúl Millán) en el caso del de México.

Tras estas etapas preliminares las siguientes sesiones fueron consagradas al ejercicio etnográfico propiamente dicho: su preparación, ejecución, presentación y análisis. Para muchos de los participantes, semejante ejercicio implicaba retos inusuales: lograr convertir la ciudad en «campo», cuando muchas veces más bien se trabaja lejos de ella; aprender a mirar en ella lo que a veces ni siquiera se ve; y sobre todo, hacer uso extenso y sacar el mejor provecho de un tiempo corto — una jornada— de observación.

Una primera fase de trabajo consistió entonces en la definición entre todas/os de una serie de preguntas pertinentes por abordar, así como la identificación de lugares desde los cuales el ejercicio etnográfico permita aportar elementos de análisis a dichas preguntas.

En Bogotá se privilegió indagar sobre el tema de la multiculturalidad y las interacciones culturales en escenarios públicos, entre otros a partir de los siguientes interrogantes: ¿Cómo la diversidad étnica, cultural, de género o sexual —reconocida legalmente por la Constitución colombiana de 1991 - se refleja o se expresa en prácticas de la cotidianidad? ¿Quiénes participan de ellas? ¿Cómo estas prácticas son susceptibles de variar en función de los actores que involucran, los lugares y horas en que se desarrollan? En paralelo, para la observación se escogieron plazas y parques centrales de la capital (San Victorino, Parque Nacional), así como restaurantes, discotecas y demás bares nocturnos (por ejemplo en 
los barrios de Santa Fe y Chapinero) o variados puntos de venta de «productos y servicios milagrosos» tales como remedios varios contra todos los males y todos tipos de brujería (Casa del Indio Amazónico, Carrera Décima); por último, también el Museo Nacional.

En México se optó por fijarse más específicamente en la relación entre espacio, prácticas de consumo e interacciones sociales, en mercados y centros comerciales: populares o exclusivos, en las calles o en espacios cerrados, destinados a ofrecer bienes alimenticios, artesanías o hierbas curativas (en las calles del centro histórico marcadas por la presencia de numerosos vendedores ambulantes, en los centros comerciales de Coapa y Pericoapa, el Mercado Artesanal de La Ciudadela, el Mercado de Sonora, el Mercado de San Juan "Pugibet"). ¿Qué intercambios se tejen entre los vendedores y los compradores, en cada uno de estos lugares de consumo? ¿Cómo son agenciados y a quiénes son destinados? ¿Qué se negocia, y entre quiénes? ¿En qué medida las prácticas de compra/venta pueden revelar otros tipos de relaciones sociales? ¿Cómo estas relaciones varían de un lugar a otro?, fueron algunas de las cuestiones por investigar, que surgieron entre los participantes.

Una vez precisados estos puntos de partida, se constituyeron grupos de trabajo, a partir de los cuáles se procedió a la preparación del ejercicio etnográfico: delimitar criterios y trazar guías de observación para saber qué se busca, porqué y para qué, definir horarios de campo y repartirse tareas -individuales o colectivas- dentro de los equipos, así como, en algunos casos, hacer una exploración inicial de los lugares escogidos.

El día siguiente fue por su parte dedicado a la acción etnográfica en sí. Al respecto, vale la pena llamar la atención sobre la variedad de medios utilizados entre los participantes. Aprovechando la posibilidad de proporcionar miradas múltiples y perspectivas comparativas en su seno, varios de los grupos decidieron abrirse por ratos, para repartirse tareas por realizar en distintos momentos del día —o la noche- en unos y otros de los escenarios escogidos para el ejercicio etnográfico. Mientras algunos limitaron su acción a la observación stricto sensu, otros se atrevieron a hacer algunas preguntas en su entorno, otros aún alcanzaron a conducir entrevistas más largas con algunos de los actores presentes en los lugares de observación. Por otra parte, entre los participantes unos no dudaron en hacer explícito su papel de observadores; otros por el contrario lo hicieron más discreto o incluso lo ocultaron -actitud que se prestó para un amplio debate sobre cuestiones de índole ética relativa al papel y las responsabilidades del investigador-. Muchos no dudaron en preparar su experiencia de terreno a través de consultas previas de documentación e información, entre otros a través de la herramienta de Internet, con el fin de ubicarse mejor frente a los contextos y las preguntas por trabajar. Así mismo, en algunos de los grupos se recurrió al papel y los lápices para dar cuenta de escenarios observados a través del dibujo; otras veces, se hizo uso de tecnologías más modernas, con cámaras fotográficas y de video. De manera más general, todas/os las/os participantes se apuntaron con entusiasmo para el reto propuesto de «etnografiar en tiempo limitado».

Los resultados de estos esfuerzos fueron compartidos en una sesión final con el conjunto de las/os participantes, durante la cual cada uno de los grupos pudo exponer los resultados de su trabajo, haciendo especial énfasis en los procedimientos empleados para llevar a cabo su «mini-investigación»: desde la definición de preguntas para abordar a partir del tema general planteado hasta la redacción de un informe preliminar alrededor de esta problemática (análisis de contenido), pasando por la detallada descripción de su experiencia de observación y la identificación paralela de logros y límites encontrados durante la jornada de «campo» (reflexión metodológica).

Si bien en los relatos de varios grupos se hizo evidente el obstáculo de la falta de tiempo para apropiarse más de los lugares seleccionados, acercarse con mayor facilidad a los actores presentes en dichos lugares y profundizar en relación con unas u otras de las preguntas planteadas, igualmente fue clara la sensación de haber podido «sacar» mucho más de lo 
que se esperaba del corto proceso de observación realizado. Con ello también se destacó la impresión general de haber logrado avanzar en el aprendizaje propuesto por el taller, que dejó un sentimiento satisfactorio de «misión cumplida» entre las/os asistentes — tanto coordinadoras/es como participantes-. Por otra parte, es de subrayar que los talleres lograron además convertirse en lugares de intercambio lo suficientemente informales para que las/os participantes puedieran atreverse a compartir todo tipo de dudas de índole metodológica o ética, en relación con sus propia experimentación del trabajo etnográfico. De manera más general, dado el éxito de estas primeras iniciativas se sugirió repetir la experiencia.

Para terminar, vale la pena destacar una serie de ideas centrales que, a manera de «conclusión» entre las/os asistentes, sobresalieron en estos dos encuentros. Ante todo, el hecho de que no existan «recetas» para hacer buenas investigaciones etnográficas pero sí unas reglas por respetar. Sin duda no es suficiente llenar registros de información a la manera de «inventarios»; es necesario conectar estos registros con la problemática trazada por la investigación. En segundo lugar - y en el mismo orden de ideas-, hay que estar abierto a las reformulaciones: si bien es necesario definir un marco teórico, hipótesis de trabajo, guías y criterios de observación previamente al campo, también es importante saber retroalimentar las preguntas y los enfoques conceptuales inicialmente esbozados, con base en el trabajo de terreno. 